\title{
Devulcanization of Natural Rubber in Composites with Distinct Crosslink Densities by Twin-Screw Extruder
}

\author{
Rafael Barbosa ${ }^{a, b *}$, Anderson Thadeu Nunes ${ }^{a}$, José Donato Ambrósio ${ }^{a, b}$ \\ ${ }^{a}$ Materials Science and Engineering Postgraduate Program - PPGCEM, Federal University of \\ São Carlos - UFSCar, São Carlos, SP, Brazil \\ ${ }^{b}$ Center of Characterization and Materials Development - CCDM, Federal University of \\ São Carlos - UFSCar, São Carlos, SP, Brazil
}

Received: December 9, 2016; Revised: March 3, 2017; Accepted: April 9, 2017

\begin{abstract}
In this study, the effects of the devulcanization process realized by an intermeshing co-rotating twin-screw extruder (ICTSE) on three vulcanized Natural Rubber (NR) composites with different crosslink densities (CD) have been investigated. The extrusion parameters were fixed, as well as the initial material granulometry and auxiliary thermoplastic added to the process. After composites vulcanization, they were characterized accordingly their soluble fraction (SF), crosslink density (CD), mechanical properties and thermogravimetry (TGA). The extrusion was performed on the vulcanized elastomers pursuing selectively crosslink rupture and the same characterization previously cited was conducted on the devulcanized material, except the mechanical properties analysis. The extrusion demonstrate effective devulcanization, evidenced in the increasing of soluble fractions, reduction in crosslink density and thermal stability gain. These results are directly affected by preliminary differences on materials structure and presence of ethylene vinyl-acetate (EVA) on extrusion.
\end{abstract}

Keywords: Devulcanization, Natural rubber, Recycle, Twin-screw extruder, EVA

\section{Introduction}

The growing demand for natural rubber (NR) has been of concern to various sectors of society. Environmental problems related to improper waste disposal generate a latent social problem, particularly nowadays (Zyca, Chikungunya, Dengue), referring to the proliferation of pests and mosquitoes, which find ideal conditions for reproduction on tire deposits due to its favorable geometry ${ }^{1}$.

Regarding the methods used to recycle the NR contained in automotive tires, is observed that few devulcanization or regeneration processes, defined by selective breaking of cross-linked rubber networks, demonstrate productive, economic and qualitative capacity. These processes are rarely finding sufficient results to compete with the methods of re-use as co-processing, granulation and rolling, which in turn does not reutilize much of the energy potential in $\mathrm{NR}$ from tires ${ }^{2,3}$. Among the main devulcanization methods currently searched, highlights processing by ultrasound ${ }^{4,5}$, microwave $^{6,7}$, chemical method ${ }^{8}$, biological treatment ${ }^{9}$ and thermomechanical ${ }^{10,11}$.

Currently, two relevant theories attempt to explain the mechanisms of crosslink selective breaking. One is based on the different chemical energies of carbon-carbon bonds (C-C $=370 \mathrm{~kJ} / \mathrm{mol})$, carbon-sulfur $(\mathrm{C}-\mathrm{S}=310 \mathrm{~kJ} / \mathrm{mol}$ ) and sulfur- sulfur ( $\mathrm{S}-\mathrm{S}=270 \mathrm{~kJ} / \mathrm{mol})$. Another is based on the distinct elastic constants of these C-C, C-S and S-S bonds,

* e-mail: rafael.bar8@gmail.com approximately $100 \mathrm{~N} / \mathrm{m}$, an intermediate value (to be probed) and $3 \mathrm{~N} / \mathrm{m}$, respectively ${ }^{12,13}$. Referring to the methods with the potential to impose, at the same time, thermal energy and elastic deformation to the material, stands out the thermomechanical devulcanization performed by twin-screw extruder.

Consistent with these theories, Zhang et al. ${ }^{14}$ used an intermeshing co-rotating twin-screw extruder (ICTSE) in various processing conditions, and added thermoplastic polymers to act as three-dimensional network swelling agents and help in the fluid pressure transfer, pursuing better selectivity at vulcanized network breakage. The temperature range used in the experiments was between $150{ }^{\circ} \mathrm{C}$ and $320^{\circ} \mathrm{C}$. The researchers found that shear stress acting on the material during the extrusion has directionality, promoting better breaking of the bonds perpendicular to the main chain, in this case the sulfidic crosslinks. Another point mentioned is the possible compatibilization effect that can be realized by the thermoplastics when they stabilize, through chemical bonds, the macrorradicals produced by rubber network breakdown, optimizing extruded material compatibility and mechanical properties. The function of radical stabilization by thermoplastics is also emphasized in Matsushita and co-workers research ${ }^{15}$. They observed a better interfacial adhesion between the devulcanized and virgin rubber when mixed (blend), occasioned by the compatibility promoted when using thermoplastics added to the extrusion process.

In the present work, the thermoplastic ethylene vinylacetate (EVA) was used as process auxiliary. EVA is a random copolymer of thermoplastic character that has excellent properties 
of ozone resistance, ageing resistance and good mechanical performance. Because of these properties, interest in blends of NR/EVA has grown in recent years ${ }^{16}$. Koshy et al. ${ }^{17}$, for example, studied the influence of the concentration of EVA and the curing system on degradation of NR/EVA blends. Jansen and Soares ${ }^{18}$ evaluated the thermal and mechanical properties of the blend, highlighting the improvement in the protection against ozone, good retention of properties after ageing and incompatibility between the blend phases, as did Koshy ${ }^{19}$ in another study.

In this way, this study aims to evaluate the process of NR devulcanization by ICTSE using three NR compositions with different crosslinking densities, adding EVA to promoting swelling and optimizing the stress distribution in the threedimensional elastomeric network.

\section{Materials and Methods}

\subsection{Materials}

The three NR composites were supplied by Amazonas Indústria e Comércio Ltda. They were prepared with composition similar to those used in tires ${ }^{20}$. An efficient vulcanization system was chosen with high accelerator/sulfur ratio. The composites formulations contained, in addition to NR matrix, stearic acid, zinc oxide $(\mathrm{ZnO})$, carbon black (CB), two antioxidants (Ant-oxy) in the same quantities, accelerators N-Cyclohexyl-2-benzothiazole sulfonamide (CBS) and tetramethyl thiuram disulfide (TMTD), naphthenic oil and variated amounts of sulfur, according to Table 1 . The change of sulfur (S) concentration aim the achievement of composites with different crosslink densities. As process auxiliary, EVA containing 19\% of vinyl acetate and produced by BRASKEM was used

\subsection{Processing}

NR composites were supplied as unvulcanized sheets. To determine temperature and time of vulcanization the three NR composites were subjected to torque rheometry in a rheometer manufactured by Monsanto, model MDR2000 , at temperatures of 130,150 and $170^{\circ} \mathrm{C}$ for 15 minutes, according to ASTM D5289-12. After the tests was selected the temperature of $130{ }^{\circ} \mathrm{C}$, and vulcanization time $\left(\mathrm{t}_{90}\right)$ of 760, 700 and 640 seconds for the samples CP1, CP2 and $\mathrm{CP} 3$, respectively. These times and temperature was chosen observing the inexistence of reversion on the rheometry curves during the analysis. Reversion is a prejudicial process inherent to NR compounds, in which the crosslinks are broken and/or desulfurized when lengthen the curing time at high temperatures ${ }^{21}$. Subsequently the composites were vulcanized by compression molding in a Marconi press, model MA-098, at $130^{\circ} \mathrm{C}$ and 15 ton of load. After vulcanization, test specimens were extracted for mechanical testing and the remaining material was ground in a Wittman cutting mill, model MAS1, until granulometry reach values lower than $2.83 \mathrm{~mm}$ (7 mesh).

The extrusion was carried out utilizing an intermeshing co-rotating twin-screw extruder (ICTSE), supplied by Coperion, with a diameter of $35 \mathrm{~mm}$ and $\mathrm{L} / \mathrm{D}=44$, with a thermal profile of $270{ }^{\circ} \mathrm{C}$ in the barrel and extrusion die, screw speed of $350 \mathrm{rpm}$ and feed rate of $3.0 \mathrm{~kg} / \mathrm{h}$. To the three vulcanized rubber composites were added $13 \mathrm{wt} \%$ of EVA, as a swelling agent and tension distributor, and processing antioxidants (1 phr) Irganox $1010^{\circledR}$ and Irgafos $168^{\circledR}(3: 1)$, before the feed.

\subsection{Characterization}

The three NR composites were characterized mechanically by tension tests in an Instron universal testing machine, model 5569, according to ASTM D412. The hardness were analyzed according to ASTM D2240 on a Barreiss Digi Test durometer. After extrusion, it was performed analysis of the gel content to identify the soluble fraction (SF) of each composite. This analysis was performed in triplicate, by placing approximately $670 \mathrm{mg}$ of ground sample in sealed metal envelopes with 120 mesh. The samples were immersed in beakers with $200 \mathrm{~mL}$ of xylene at $75^{\circ} \mathrm{C}$ for $6 \mathrm{~h}$. SF was obtained by the mass difference of the sample before $\left(\mathrm{M}^{1}\right)$ and after $\left(\mathrm{M}^{2}\right)$ extraction in xylene, according to equation 1 .

$$
S F(\%)=\frac{M^{1}-M^{2}}{M^{1}} \times 100
$$

The crosslink density, before and after extrusion, was obtained according to Flory-Rehner study of the solubility and swell of three-dimensional networks in the presence of organic solvents ${ }^{22}$. The present study does not use the Kraus $^{23}$ correction due to the assurance that the carbon black used is the same in all samples. Approximately $2.0 \pm 0.1 \mathrm{~g}$ of sample were immersed in $200 \mathrm{~mL}$ of xylene for $24 \mathrm{~h}$,

Table 1. Formulation of the Natural Rubber Composites.

\begin{tabular}{cccccccccccc}
\hline \multicolumn{10}{c}{ Component (phr) } \\
\hline NR & $\begin{array}{c}\text { Stearic } \\
\text { acid }\end{array}$ & ZnO & Carbon Black & $\begin{array}{c}\text { Ant-Oxy } \\
\text { A1 e A2 }\end{array}$ & CBS & TMTD & Naphthenic oil & \multicolumn{2}{c}{ Sulfur (S) } \\
\hline 100 & 2.5 & 1.5 & 50 & 2.0 & 3.5 & 0.3 & 15.0 & 0.5 & 1.0 & 1.5 \\
\hline
\end{tabular}

A1 = Antioxidant TMQ: Polymerized 2,2,4-trimethyl-1,2-dihydroquinoline

A2 = Antioxidant 6PPD: N(1,3-dimethyl-butyl)-N'-phenyl-P-phenylenediamine. 
at room temperature, to reach equilibrium swelling. The crosslink density was calculated according to the Flory-Rehner equation (2) where $v_{e}\left(\mathrm{~mol} / \mathrm{cm}^{3}\right)$ is the crosslink density, $v_{r}$ is the rubber volume fraction in equilibrium in the gel, $V_{1}$ is the solvent molar volume $\left(\mathrm{cm}^{3} / \mathrm{mol}\right)$ and $\chi$ is a rubbersolvent interaction constant (Flory-Huggins constant). The volume fraction of rubber in equilibrium $\left(V_{r}\right)$ can be found by Equation 3, according to ASTM D6814.

$$
v_{e}=\frac{-\left[\ln \left(1-V_{r}\right)+V_{r}+\chi V_{r}^{2}\right]}{\left[V_{1}\left(V_{r}^{1 / 3}-V_{r}\right) / 2\right]}
$$

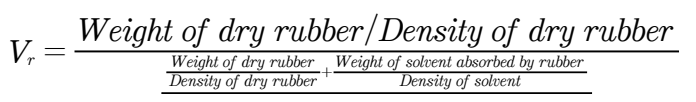

Were also determined the percent devulcanization, considered the ratio of the crosslink density difference before $\left(v_{e b}\right)$ and after $\left(v_{e a}\right)$ extrusion, and the crosslink density before extrusion $\left(v_{e b}\right)$, as represented in equation 4 .

$$
\text { Devulcanization }(\%)=\frac{\nu_{\mathrm{eb}}-\nu_{\mathrm{ea}}}{\nu_{\mathrm{eb}}} \times 100
$$

Finally, the thermogravimetric analysis (TGA) and derivative thermogravimetry (DTG) curves were obtained in a thermal analyzer TA2000, with thermogravimetric module Hi-Res TGA 2950, manufactured by TA Instruments. The heating rate of $20^{\circ} \mathrm{C} / \mathrm{min}$ from $30^{\circ} \mathrm{C}$ to $700{ }^{\circ} \mathrm{C}$ was used in nitrogen atmosphere until $550^{\circ} \mathrm{C}$, and then in oxygen atmosphere for carbon black content determination.

\section{Results and discussion}

The mechanical properties of the three composites, with distinct sulfur contents were tested for checking that the vulcanization was performed correctly, and the capacity of crosslinking was satisfactory resulting in varied mechanical performances in different compositions. It is known that the amount of sulfur is essential for the crosslinking process, however the sulfidic bond type/length is more closely correlated with the accelerator/sulfur ratio $(\mathrm{A} / \mathrm{S})$ and the curing conditions. In systems with high $\mathrm{A} / \mathrm{S}$, the monosulfidic crosslinks are most abundant than in systems with low $\mathrm{A} / \mathrm{S}$, where di- and polysulfidic crosslinks have an opposite behavior $^{24,25}$. The effect of this difference in the crosslinks length leads to different results on the material properties, being monosulfidic bonds precursors of best results in heat aging and chemical stability, while di- and polysulfidic bonds present better mechanical results. This mechanical performance optimization is referred to the greater number of long distance interactions and ability of these links to break and reform instantly ${ }^{26}$. Table 2 shows results of mechanical tests for vulcanized composites, also relating the A/S ratio, the maximum torque reached in rheometry $\left(\mathrm{T}_{\max }\right)$ and the crosslink density (CD) obtained in solvent swelling test.

Table 2 shows that there is a good correlation between $\mathrm{T}_{\text {max }}$ and the mechanical properties. These results are in accordance with the achievement of higher crosslink densities, due to the increased sulfur, and indicate a possible variation in the crosslink length, with larger amounts of di- and polysulfide in the lowest $\mathrm{A} / \mathrm{S}$ ratios. The increase in elastic modulus and hardness and decrease of the elongation at break as function of the sulfur content shown that the rubber three dimensional structure is more anchored, compact and with greater impediment to flow between the polymer chains. The crosslink density found also evidenced this same tendency. Figure 1 shows the correlation between $\mathrm{CD}$, elastic modulus at $300 \%$ strain and elongation at break, showing greats determination coefficient values in linear regression.

Jana and $\operatorname{Das}^{27}$ in their research also studied the effect of variation in the vulcanizating system on natural rubber composites, however increasing the accelerator amount as the sulphur concentration decreases on tree composites with high, medium and lower sulphur contents. The results demonstrate that with the increase of sulphur, hardness and crosslink density showed a proportional performance with this content, although the tensile properties as modulus, elongation at break and tensile strength exhibited similar values. These demonstrate the important correlation between the mechanical properties and the $\mathrm{A} / \mathrm{S}$ ratios, when the lack of sulphur was compensated with the increase in process efficiency when adding more accelerator. In this study, the accelerators concentration was fixed, resulting in mechanical properties very proportional to the sulphur amount variation. In the literature, a wide range of mechanical properties values can be found, being extremely influenced by rubber compounding formulation ${ }^{9,10,11}$.

Table 2 also shows that the tensile strength has different behavior regarding other properties, because as the standard deviations coincide the tensile strengths are equal. This could be explained by the depreciation of the flow induced crystallization capacity, phenomenon intrinsic to NR composites

Table 2. Mechanical and physical properties of vulcanized NR composites.

\begin{tabular}{lcccccccc}
\hline Sample & $\mathrm{A} / \mathrm{S}$ & $\begin{array}{c}\mathrm{T}_{\mathrm{Max}} \\
(\mathrm{dN} \cdot \mathrm{m})\end{array}$ & $\begin{array}{c}\text { Tensile } \\
\text { strength }(\mathrm{MPa})\end{array}$ & $\begin{array}{c}\text { Modulus } \\
100 \%^{1}(\mathrm{MPa})\end{array}$ & $\begin{array}{c}\text { Modulus } \\
30 \%^{2}(\mathrm{MPa})\end{array}$ & $\begin{array}{c}\text { Elongation at } \\
\text { break }(\%)\end{array}$ & $\begin{array}{c}\text { Hardness } \\
(\text { Shore A) }\end{array}$ & $\begin{array}{c}\text { Crosslink } \\
\text { Density } \\
\left(10^{-5} \mathrm{~mol}^{2} \mathrm{~cm}^{3}\right)\end{array}$ \\
\hline CP1 & 7.6 & 8.7 & $23.5 \pm 0.2$ & $2.4 \pm 0.3$ & $4.7 \pm 0.3$ & $541.9 \pm 8.1$ & $58.8 \pm 0.7$ & 24.9 \\
CP2 & 3.8 & 9.5 & $23.8 \pm 1.1$ & $3.2 \pm 0.5$ & $5.5 \pm 0.2$ & $491.5 \pm 24.1$ & $63.2 \pm 0.2$ & 30.8 \\
CP3 & 2.5 & 9.8 & $22.5 \pm 0.7$ & $4.1 \pm 0.3$ & $6.6 \pm 0.4$ & $413.5 \pm 14.9$ & $64.6 \pm 0.3$ & 37.4 \\
\hline
\end{tabular}

${ }^{1}$ Modulus at $100 \%$ of elongation and ${ }^{2}$ Modulus at $300 \%$ of elongation, both during tension test. 


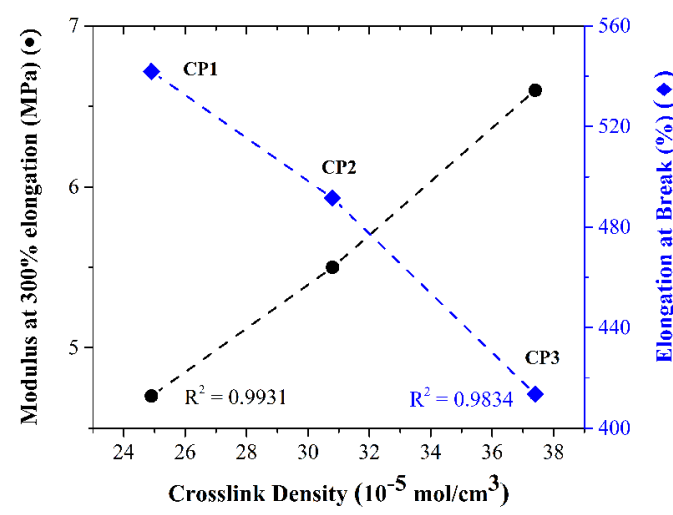

Figure 1. Correlation between crosslink density and tension properties of vulcanized NR composites with different sulfur contents.

when subjected to deformation ${ }^{28}$. When the crosslink density increases the flow between the polymer chains is constrained, reducing the strain-induced crystallization and thus the tensile strength.

Soluble fraction (SF) was evaluated with xylene as solvent for the three vulcanized NR composites before and after extrusion. The SF obtained may be composed by xylene soluble additives residue, present in the composites, as well as the thermoplastic polymer (EVA) and devulcanized NR, that were soluble in hot xylene. Figure 2 exhibit comparative results of SF extracted from NR vulcanized composites, before and after extrusion. It is observed that SF was low for vulcanized and not-extruded composites resulting in values around $12 \mathrm{wt} \%$. Low molecular weight and/or unreacted organic materials, by-products such as vulcanization accelerators, process oil and even free sulfur may compose these soluble parts. In contrast, the three extruded composites (CP1E, CP2E and CP3E) exhibited high SF showing the chains segments liberation from the vulcanized NR reticulum, as consequence of the sulfur crosslinks breakdown. It should also be noted that might be ocurred degradation of the main chain, with the release of larger polymer portion that contributed to this increase, as explained by Horikx's $\mathrm{s}^{29}$ theory. According to this theory, the soluble fraction rising is more prominent and ease when main chain breakdown occurs, liberating larger segments with less breakages, in comparison to SF obtained when selective crosslink rupture take place.

Figure 2 presents the soluble fractions and relative soluble fractions found, with the relative fractions calculated in the devulcanized compounds deducing the EVA soluble fraction.

The analysis of the percent devulcanization, present in Table 3 , shows that there is a greater propensity of crosslink breakage in more elastically rigid composites that are characterized by the higher sulfur concentration, higher crosslink density and hence superior elastic modulus. In this sense, the unequal reduction of the crosslinks densities could be attributed to two concomitant phenomena. The first one is

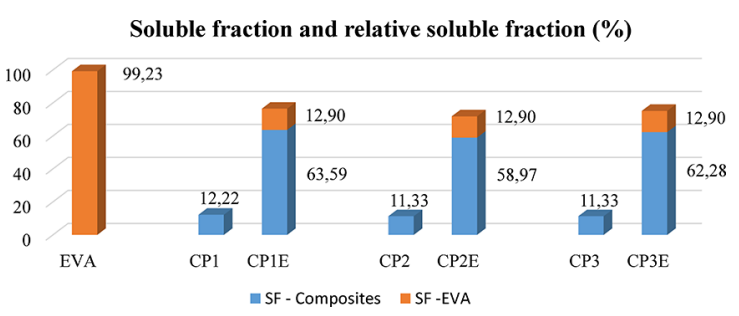

Figure 2. Soluble fractions of EVA and NR composites before (CP1, $\mathrm{CP} 2, \mathrm{CP} 3)$ and after extrusion (CP1E, CP2E, CP3E), in percentage.

the proportionality of the chemical bond types, wherein the $\mathrm{A} / \mathrm{S}$ ratio decreases from $\mathrm{CP} 1$ to $\mathrm{CP} 3$, resulting in a higher degree of di- and polysulfidic bonds, with a higher proportion of C-S and S-S bonds ${ }^{24}$. As previously commented, when the sulfur atoms number increases in a crosslink it will be more susceptible to break by shear stress and thermal energy. On the other hand, this more pronounced decrease in the crosslink density presented by the composites with more compact three-dimensional network could be explained by the greater homogeneity in the stress distribution provided by the molten EVA during the extrusion. EVA presents better efficacy in hydrodynamic swelling in the composite networks with more compact structure, in this case the higher CD composites, proportioning better distribution of the shear stress between the chain links.

Table 3. Crosslink densities of the samples, before and after extrusion, and the consequent percentage of devulcanization.

\begin{tabular}{lccc}
\hline Sample & $\begin{array}{c}\mathrm{CD}_{\mathrm{b}}{ }^{1} \\
\left(10^{-5} \mathrm{~mol} / \mathrm{cm}^{3}\right)\end{array}$ & $\begin{array}{c}\mathrm{CD}_{\mathrm{a}}{ }^{2} \\
\left(10^{-5} \mathrm{~mol} / \mathrm{cm}^{3}\right)\end{array}$ & $\begin{array}{c}\text { Devulcanization } \\
(\%)\end{array}$ \\
\hline $\mathrm{CP} 1$ & 24.9 & 6.2 & 75.1 \\
$\mathrm{CP} 2$ & 30.8 & 6.9 & 77.6 \\
$\mathrm{CP} 3$ & 37.4 & 8.1 & 78.3 \\
\hline
\end{tabular}

${ }^{1} \mathrm{CD}_{\mathrm{b}}$ and ${ }^{2} \mathrm{CD}_{\mathrm{a}}$ : Crosslink density before and after extrusion, respectively.

The thermal stability of vulcanized NR composites before and after extrusion was evaluated by thermogravimetric analysis (TGA) and the results can be observed in Figure 3. The TG results shown that the three extruded NR composites presented degradation temperature peaks of the NR that were slightly higher to same not extruded composites. This result contradict the expected considering that the extrusion in the presence of oxygen, under severe temperature and high shear conditions, tends to deteriorate the rubber, reducing its molecular weight and rising low molar mass by-products presence. This would imply in lower degradation for the extruded NR composites ${ }^{30}$. However, the extruded composites contain EVA in their composition, which does not occur in the non-extruded samples. Thus, one hypothesis for this analysis is that EVA could have acted as radical stabilizer, neutralizing active sites, which originated from the breakdown of crosslinks (C-S and S-S) and main chain 
(C-C). Matshushita ${ }^{15}$ and $\mathrm{Kleps}^{30}$ also announced this opposite of expected effect, demonstrating better thermal results after severe processing conditions.
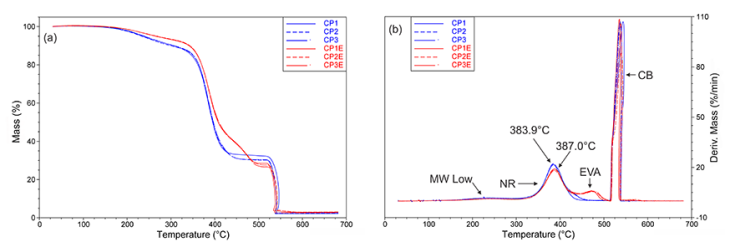

Figure 3. Thermogravimetric curves of NR vulcanized composites before and after extrusion. (a) Thermogravimetric and (b) Derivative Thermogravimetric curves. $\mathrm{CP} 1\left(383,9^{\circ} \mathrm{C}\right)$ and $\mathrm{CP} 1 \mathrm{E}\left(387,0^{\circ} \mathrm{C}\right)$ degradation temperature peaks can be observed.

Table 4 shows the weight loss $\left(\mathrm{W}_{\text {loss }}\right)$ and peak temperatures in the degradation intervals of the different components present in vulcanized NR composites before and after extrusion. In the temperature interval between 100 ${ }^{\circ} \mathrm{C}$ and $300{ }^{\circ} \mathrm{C}$ is observed mass losses between 7 and $11 \%$, referred to the decomposition of additives and residues with low molecular weight as oils, oligomers and vulcanization and devulcanization process residue ${ }^{31}$. The lowest mass loss in this range presented by the extruded composites might be explained by the EVA presence, added on the extrusion. Another possibility would be the stabilization caused by EVA on the composite, as discussed above. Extruded composites were expected to exhibit a greater amount of low molecular weight materials due to the intrinsic degradation of the polymer chains during the extrusion process. Again, this probability did not occurred due to the presence of EVA. NR degradation appears in the temperature range from 300 ${ }^{\circ} \mathrm{C}$ to $450{ }^{\circ} \mathrm{C}$, with a peak occurring around $385^{\circ} \mathrm{C}^{30}$. EVA degradation occurs in the temperature range from $410^{\circ} \mathrm{C}$ to $500{ }^{\circ} \mathrm{C}$, with a peak around $475^{\circ} \mathrm{C}^{18}$. The final weight loss interval occurred whithin the exchange of feed gas, from oxygen to nitrogen, at $550^{\circ} \mathrm{C}$ caused by carbon black thermal oxidation.

Analyzing the costs involved in this devulcanitaion process realized by ICTSE, it can be observed that a high productivity with a low cost was obtained, in relation to the virgin product. In this study, the acquisition cost of the virgin
BN composite was US $\$ 4.00 / \mathrm{kg}$, being this value used to evaluate the method viability. Using an ICTSE ( $D=35.0$ $\mathrm{mm}$ and $\mathrm{L} / \mathrm{D}=44$ ) in industrial condition, the extrusion provides around $30 \mathrm{~kg} / \mathrm{h}$, with an electric current of around $50 \mathrm{~A}$ in a $220 \mathrm{~V}$ network. Simulating the operation with a value of USD $\$ 0.15 / \mathrm{kWh}$, there is a cost of $\$ 1.55$ per hour of power consumption. Also, the total expenses with an operator that costs about $\$ 1,000.00 /$ month, needs to be added, which is equivalent to $\$ 5.60$ /hour. Another important expense is the price of EVA, purchased for $\$ 2.15 / \mathrm{kg}$, which is incorporated in $13 \%(\mathrm{~W} / \mathrm{W})$ at extrusion. As the process extrudes around $30.00 \mathrm{~kg} / \mathrm{h}$ of material, $3.90 \mathrm{~kg}$ of EVA would be consumed, with a total cost of $\$ 8.50$. Adding these expenses and considering zero cost in the acquisition of the material to be recycled, we have the total expense of about $\$ 15.65$ for the devulcanization of $30.00 \mathrm{~kg}$ of NR composite with EVA, in one hour of operation. This value for $\mathrm{BN}$ composite recycling can be compared to the price of $30 \mathrm{~kg}$ of virgin NR composite (extruder capacity in one hour) which is about $\$ 120.00$. In this way, the cost of about $\$ 15.65$ to recycle $30.00 \mathrm{~kg}$ of waste NR composite would be equivalent to approximately $13 \%$ of the $\$ 120.00$ needed to acquire $30.00 \mathrm{~kg}$ of virgin NR composite. Obviously, the cost analysis is rather simplified, however it considers the main costs involved in NR composite recycling, demonstrating that it would be a viable sustainable activity.

\section{Conclusion}

According to obtained results, thermomechanical devulcanization of the natural rubber (NR) used in tire composites, by twin-screw extruder, exhibited a high potential for application. A difference of this study, from others previously realized, is that in this case was applied in a NR composite similar to those used in automotive tires, with fully known formulation. The results present a high percentage of devulcanization, observed through soluble fraction increase, demonstrating a tendency of better performance in networks with more compact structures. This effect could be caused by the addition of the thermoplastic EVA, which acted as swelling auxiliary in the crosslinked network and provided better stress distribution between crosslinks.

Table 4. Weight loss and degradation temperature peak obtained on the thermogravimetric analysis.

\begin{tabular}{lcccccccc}
\hline \multirow{2}{*}{ Sample } & $\begin{array}{c}\text { Low } \\
\text { Molecular } \\
\text { Weights }\end{array}$ & \multicolumn{2}{c}{ Natural Rubber } & \multicolumn{2}{c}{ EVA } & \multicolumn{2}{c}{ Carbon Black } & Residue \\
\cline { 2 - 9 } & $\mathrm{W}_{\text {loss }}(\%)$ & $\mathrm{W}_{\text {loss }}(\%)$ & $\mathrm{T}_{\text {peak }}\left({ }^{\circ} \mathrm{C}\right)$ & $\mathrm{W}_{\text {loss }}(\%)$ & $\mathrm{T}_{\text {peak }}\left({ }^{\circ} \mathrm{C}\right)$ & $\mathrm{W}_{\text {loss }}(\%)$ & $\mathrm{T}_{\text {peak }}\left({ }^{\circ} \mathrm{C}\right)$ & $\mathrm{W}_{\text {peak }}(\%)$ \\
\hline $\mathrm{CP} 1$ & 9.6 & 57.3 & 383.9 & - & - & 30.1 & 543.6 & 2.1 \\
$\mathrm{CP} 1 \mathrm{E}$ & 7.2 & 51.9 & 387.0 & 12.4 & 473.5 & 25.5 & 535.7 & 2.9 \\
$\mathrm{CP} 2$ & 10.9 & 58.8 & 385.1 & - & - & 27.9 & 537.2 & 2.4 \\
$\mathrm{CP} 2 \mathrm{E}$ & 6.9 & 53.4 & 386.9 & 12.1 & 479.0 & 23.8 & 539.5 & 2.9 \\
$\mathrm{CP} 3$ & 8.3 & 61.3 & 385.2 & - & - & 27.9 & 537.1 & 2.6 \\
$\mathrm{CP} 3 \mathrm{E}$ & 7.3 & 53.3 & 387.1 & 12.7 & 478.8 & 24.0 & 538.6 & 2.6 \\
\hline
\end{tabular}


EVA can also have stabilized the macrorradicals generated in the crosslinks and main chain breakdown. This is observed in the thermogravimetric curves of the NR composites processed with EVA, whose shown slight increase in the NR degradation temperature peak, and displacement of its degradation range to higher temperatures, when compared with non-extruded composites. This counteracts the effects usually found considering the extrusion tendency to increase the propension of NR degradation. The same contrary tendency was observed on the concentration of low molecular weight decomposition products, since the NR extruded composites showed less weight loss than non-extruded in this temperature range.

It was concluded that the intermeshing and co-rotating twin-screw extrusion (ICTSE) effectively broke the elastomer-vulcanized network, and the use of EVA in the devulcanization process yielded in several positive effects, helping in the material stress distribution and thermal stability maintenance during the process.

\section{Acknowledgements}

The authors would like to thank PPGCEM/UFSCar and CCDM/UFSCar for the laboratory facilities and technical support, CAPES for the financial support and $22^{\circ} \mathrm{CBECIMAT}$ organization for the science progress commitment.

\section{References}

1. Imbernon L, Norvez S. From landfilling to vitrimer chemistry in rubber life cycle. European Polymer Journal. 2016;82:347376. DOI: 10.1016/j.eurpolymj.2016.03.016

2. Isayev AI. Recycling of rubbers. In: Mark JE, Erman B, Eirich FR. Science and Technology of Rubber (Third Edition). Burlington: Academic Press; 2005. p. 663-701. DOI: 10.1016/ B978-012464786-2/50018-3

3. Adhikari B, De D, Maiti S. Reclamation and recycling of waste rubber. Progress in Polymer Science. 2000; 25(7):909-948. DOI: $10.1016 / \mathrm{S} 0079-6700(00) 00020-4$

4. Tapale M, Isayev AI. Continuous ultrasonic devulcanization of unfilled NR vulcanizates. Journal of Applied Polymer Science. 1998;70(10):2007-2019. DOI: 10.1002/(SICI)10974628(19981205)70:10<2007::AID-APP17>3.0.CO;2-D

5. Mangili I, Lasagni M, Huang K, Isayev AI. Modeling and optimization of ultrasonic devulcanization using the response surface methodology based on central composite face-centered design. Chemometrics and Intelligent Laboratory Systems. 2015;144:1-10. DOI: 10.1016/j.chemolab.2015.03.003

6. Molanorouzi M, Mohaved SO. Reclaiming waste tire rubber by an irradiation technique. Polymer Degradation and Stability. 2016;128:115-125. DOI: 10.1016/j.polymdegradstab.2016.03.009

7. Colom X, Faliq A, Formela K, Cañavate J. FTIR spectroscopic and thermogravimetric characterization of ground tyre rubber devulcanized by microwave treatment. Polymer Testing. 2016;52:200-208. DOI: 10.1016/j.polymertesting.2016.04.020
8. Sabzekar M, Chenar MP, Mortazavi SM, Kariminejad M, Asadi $\mathrm{S}$, Gholamhossein Zohuri G. Influence of process variables on chemical devulcanization of sulfur-cured natural rubber. Polymer Degradation and Stability. 2015;118:88-95. DOI: 10.1016/j.polymdegradstab.2015.04.013

9. Li Y, Zhao S, Wang Y. Microbial Desulfurization of Ground Tire Rubber by Sphingomonas sp.: A Novel Technology for Crumb Rubber Composites. Journal of Polymers and the Environment. 2011;20(2):372-380. DOI: 10.1007/s10924-011-0386-1

10. Maridass B, Gupta BR. Performance optimization of a counter rotating twin screw extruder for recycling natural rubber vulcanizates using response surface methodology. Polymer Testing. 2004;23(4):377-385. DOI: 10.1016/j.polymertesting.2003.10.005

11. Sutanto P, Picchioni F, Janssen LPBM. The use of experimental design to study the responses of continuous devulcanization processes. Journal of Applied Polymer Science. 2006;102(5):50285038. DOI: $10.1002 /$ app.25022

12. Fukumori K, Matsushita M. Material Recycling Technology of Crosslinked Rubber Waste. R\&D Review of Toyota $C R D L$. 2002;38(1):39-47.

13. Myhre M, Saiwari S, Dierkes W, Noordermeer J. Rubber recycling: chemistry, processing, and applications. Rubber Chemistry and Technology. 2012;85(3):408-449. DOI: 10.5254/ rct.12.87973

14. Zhang Y, Shen J, Chen T, Xu Z, Chen X, Zhang M, inventors; Zhang Y, Ji S, Chen T, Xu Z, Chen X, Zhang M, assignees. Process for devulcanization of rubber. United States patent US 20090082475. 2009 Mar 26.

15. Matsushita M, Mouri M, Okamoto H, Fukumori K, Sato N, Fukuta M, et al., inventors; Kabushiki Kaisha Toyota Chuo Kenyusho, Toyoda Gosei Co. Ltd., Toyota Jidosha Kabushiki Kaisha, assignees. Method of reclaiming crosslinked rubber. United States patent US 6632918 B1. 2003 Oct 14.

16. Thomas $\mathrm{S}$, Chan $\mathrm{CH}$, Pothen LA, Rajisha KR, Maria $\mathrm{H}$, eds. Natural Rubber Materials: Volume 1: Blends and IPNs. Cambridge: Royal Society of Chemistry; 2013.

17. Koshy AT, Kuriakose B, Thomas S. Studies on the effect of blend ratio and cure system on the degradation of natural rubberethylene-vinyl acetate rubber blends. Polymer Degradation and Stability. 1992;36(2):137-147. DOI: 10.1016/01413910(92)90150-4

18. Jansen P, Soares BG. Effect of compatibilizer and curing system on the thermal degradation of natural rubber/EVA copolymer blends. Polymer Degradation and Stability. 1996;52(1):95-99. DOI: $10.1016 / 0141-3910(95) 00238-3$

19. Koshy AT, Kuriakose B, Thomas S, Varghese S. Studies on the effect of blend ratio and crosslinking system on thermal, X-ray and dynamic mechanical properties of blends of natural rubber and ethylene-vinyl acetate copolymer. Polymer. 1993;34:(16)34283436. DOI: 10.1016/0032-3861(93)90472-M

20. Bhowmick AK, Hall MM, Benarey AH. Rubber Products Manufacturing Technology. New York: Marcel Dekker; 1994.

21. Rodgers B. Rubber Compounding: Chemistry and Applications. New York: Marcel Dekker; 2004. 
22. Flory PJ, Rehner J Jr. Statistical Mechanics of Cross-Linked Polymer Networks II. Swelling. The Journal of Chemical Physics. 1943;11:521-526. DOI: 10.1063/1.1723792

23. Kraus G. Swelling of filler-reinforced vulcanizates. Journal of Applied Polymer Science. 1963;7(3):861-871. DOI: 10.1002/ app.1963.070070306

24. Coran AY. Chemistry of the vulcanization and protection of elastomers: A review of the achievements. Journal of Applied Polymer Science. 2003;87(1):24-30. DOI: 10.1002/app.11659

25. Akiba M, Hashim AS. Vulcanization and crosslinking in elastomers. Progress in Polymer Science. 1997;22(3):475-521. DOI: $10.1016 / \mathrm{S} 0079-6700(96) 00015-9$

26. Morrison NJ, Porter M. Temperature Effects on the Stability of Intermediates and Crosslinks in Sulfur Vulcanization. Rubber Chemistry and Technology. 1984;57(1):63-85. DOI: $10.5254 / 1.3536002$
27. Jana GK, Das CK. Recycling natural rubber vulcanizates through mechanochemical devulcanization. Macromolecular Research. 2005;13(1):30-38. DOI: 10.1007/BF03219012

28. Hofmann W. Rubber Technology Handbook. Munich Vienna: Hanser Publishers; 1989.

29. Horikx MM. Chain scissions in a polymer network. Journal of Polymer Science. 1956;19(93):445-454. DOI: 10.1002/ pol.1956.120199305

30. Kleps T, Piaskiewicz M, Parasiewicz W. The Use of Thermogravimetry in the Study of Rubber Devulcanization. Journal of Thermal Analysis and Calorimetry. 2000;60(1):271277. DOI: $10.1023 / \mathrm{A}: 1010134315762$

31. Scuracchio CH, Waki DA, da Silva MLCP. Thermal analysis of ground tire rubber devulcanized by microwaves. Journal of Thermal Analysis and Calorimetry. 2007;87(3):893-897. DOI: 10.1007/s10973-005-7419-8 